\title{
Complexation Study of Alkali Metal Ions by Crown Ether Derivatives in Nonaqueous Solvents by Potentiometric Methods
}

\author{
J.M. Caridade Costa ${ }^{a) \text {, * and P.M.S. Rodrigues }}{ }^{\text {b) }}$ \\ ${ }^{a)}$ Departamento de Química, Universidade de Coimbra, P-3004-535 Coimbra, Portugal. \\ ${ }^{b)}$ Instituto Politécnico da Guarda, P-6300 Guarda, Portugal
}

Received 02 August 2002; Accepted in revised form 25 October 2002

\begin{abstract}
The formation and stability of alkali metal complexes with crown ethers containing an anthraquinone unit has been investigated in methanol and acetonitrile solutions by potentiometric methods. Complexes of 1:1 stoichiometry were observed for all the studied systems; 2:1 complexes were only detected for the larger alkali cations $\left(\mathrm{Rb}^{+}\right.$and $\left.\mathrm{Cs}^{+}\right)$and with the ligand with the larger macrocyclic cavity (AQ21C7). The 1:1 complexes with the highest stability are formed by $\mathrm{K}^{+}$ion with the AQ18C6 ligand and by $\mathrm{Cs}^{+}$ion with the AQ21C7 ligand. In the alkali cation group and in both solvents, the stability of the 1:1 complexes was found to vary in the following order, $\mathrm{Li}^{+}<\mathrm{Na}^{+}<\mathrm{K}^{+}>\mathrm{Rb}^{+}>\mathrm{Cs}^{+}$with AQ18C6 ligand and $\mathrm{Li}^{+}<\mathrm{Na}^{+}<$ $\mathrm{K}^{+}<\mathrm{Rb}^{+}<\mathrm{Cs}^{+}$with AQ21C7 ligand. The stability of the complexes of AQ21C7 is smaller than those of their AQ18C6 analogues. The stability of the silver complexes of AQ18C6 and $\mathrm{AQ} 21 \mathrm{C} 7$ was found to be smaller than that of the alkali metal complexes of comparable size. The incorporation of an anthraquinone unit in crown ethers induces some loss of complexation stability for all cations, but the cation selectivity is not changed. The results obtained are analysed and discussed regarding the effects of the relative sizes of the cations and macrocyclic cavity of the ligands, solvating ability of the solvents towards the cation and influence of the anthraquinone unit.
\end{abstract}

Keywords: crown ether derivatives; alkali metal ions; complexation; potentiometry

\section{Introduction}

One of most interesting properties of the macrocyclic polyethers is their capacity to recognise molecules and ions as a consequence of their ability to form with these chemical species, compounds of high stability and in a selective way [1-4]. These characteristics are relevant on the selective transport of amino acids or metal ions across

\footnotetext{
*Corresponding author. E-mail address: caridade@ci.uc.pt; Fax: 351239827703
} 
membranes and can serve as models in important biological processes as the enzymeionic substract interactions [1,5-7]. Their use as a neutral carrier in liquid membranes of ion selective electrodes is another important analytical application.[8,9].

The selective interaction process between macrocyclic polyethers and metal ions requires among other conditions, structural characteristics and dimensions of the cavity formed by the polyether ring so that it can be capable to fit suitably to a specific cation[10,11]. The efficiency of interaction may also be affected by the nature of the metal ion and by the number, distance and orientation of the donor atoms of the ligand that are structurally accessible to the complexed cation $[12,13]$. The ability of the solvent molecules to compete with the donor atoms of the ligand towards the coordination sites of the cation, is another factor that can thermodynamically influence the complexation process [14].

We are especially interested on the thermodynamic of complexation and selectivity profiles of crown ethers attached to an anthraquinone unit in the neutral and reduced states towards alkali and alkaline earth cations. Previously we have presented a study of the complexation of these crown ether derivatives in the reduced state with alkali and alkaline earth metal ions by cyclic voltammetry $[15,16]$. The anthraquinone has shown to be an efficient redox centre on the complexation of macrocyclic ligands, owing to the ready reversibility of its redox system and thermodynamic stability of its reduced forms [15-18]. Electrochemical reduction of these ligands leads to an increase of their negative charge, which in turn enhances the binding to the cation. Moreover such systems have behaved as complexing agents of different strength to alkali and alkaline earth cations. In this paper, we report and discuss the relative affinity of neutral crown ether derivatives of anthraquinone with alkali metal ions, obtained from the stability constants by potentiometric measurements, in methanol and acetonitrile solutions.

\section{Experimental}

The solutions of the alkali cations were prepared from their perchlorates (Aldrich) of the highest purity commercially available and were used without further purification after dried in vacuum at $90{ }^{\circ} \mathrm{C}$ for $48 \mathrm{~h}$. Owing to very weak solubility of potassium perchlorate in the previously mentioned solvents, the respective tetraphenylborate was used, being prepared and purified according to published procedures [19]. The concentrations of the alkali metal cations were checked by atomic absorption 
spectroscopy. Silver nitrate (Merck) was dried at $80{ }^{\circ} \mathrm{C}$ in vacuum and in the absence of light. Tetrabutylammonium perchlorate (Fluka) was recrystallized from ethyl acetate and water and dried in vacuum at $110^{\circ} \mathrm{C}$ for $48 \mathrm{~h}$. The studied synthetic crown ether derivatives were prepared and purified as previously described [15]. Acetonitrile (gradient grade for chromatography, Merck) and methanol (HPLC quality, Lab-Scan) were used without additional purification.

The experimental data for the determination of the stability constants of the alkali ion complexes were obtained from a competitive complexation reaction between $\mathrm{Ag}^{+}$and $\mathrm{M}^{+}$(alkali cation) for the ligand [20,21]. This was carried out owing to the difficulty to identify and measure the concentration of alkali cations in methanol and acetonitrile. To monitor the potential (and the corresponding concentration of the free silver ion) in equilibrium, we have used an electrode that detects the silver ion.

As a first step, we have estimated the stability constants of the silver complexes through direct titrations in solutions of varied concentrations of ligand $\left(C_{L}=2.8 \times 10^{-4}-6.2 \times 10^{-3}\right.$ mol dm$\left.{ }^{-3}\right)$ with silver nitrate solutions $\left(\mathrm{C}_{\mathrm{Ag}}=2.0 \times 10^{-5}-1.0 \times 10^{-2} \mathrm{~mol} \mathrm{dm}^{-3}\right)$ and measured the potential with a selective electrode. A competitive complexation reaction was performed as a second independent experiment using the same experimental procedure this time to titrate solutions containing a mixture of ligand $\left(C_{L}=1.2 \times 10^{-4}-2.3 \times 10^{-3} \mathrm{~mol}\right.$ $\left.\mathrm{dm}^{-3}\right)$ and alkali salt $\left(\mathrm{C}_{\mathrm{M}}=1.2 \times 10^{-3}-1.7 \times 10^{-2} \mathrm{~mol} \mathrm{dm}^{-3}\right)$ with silver nitrate solutions $\left(\mathrm{C}_{\mathrm{Ag}}=5.0 \times 10^{-6}-7.8 \times 10^{-3} \mathrm{~mol} \mathrm{\textrm {dm } ^ { - 3 }}\right)$. The stability constants for the complexation of the alkali cations were obtained from the measured potential and from the previously calculated equilibrium constant of the silver complexes. We have used different total concentrations and concentration ratios of ligands and metal ions to study the wider range of allowed concentrations.

The ionic strength of the solutions was kept approximately constant at $0.1 \mathrm{~mol} \mathrm{dm}{ }^{-3}$ using tetrabutylammonium perchlorate (TBAP) as supporting electrolyte. The solutions were saturated with a stream of oxygen-free nitrogen previously presaturated with solvent. During each titration experiment an inert atmosphere was continuously maintained over the solution. All the experiments were controlled at $25 \pm 0.1^{\circ} \mathrm{C}$.

Depending on the solvent, we have used two different cells to measure the potential of the solutions after the complexation equilibrium has been established. In the methanol medium a cell consisting of a selective electrode of silver/silver sulphide (Orion, model 94-16) as indicator and an electrode of silver/silver chloride of double junction (Orion, 
model 90-02) as reference, was used. In the acetonitrile medium we have used a cell composed by a silver wire electrode (Metrohm, model 6.0331.010) as indicator and separately another silver wire electrode dipped into a solution of $0.01 \mathrm{~mol} \mathrm{dm}^{-3}$ silver nitrate as reference; a salt bridge containing $0.1 \mathrm{~mol} \mathrm{dm}^{-3}$ TBAP in acetonitrile made the connection between the two half-cells. In the study of the sodium complexation in methanol we also directly monitored the potential (and the uncomplexed $\mathrm{Na}^{+}$ concentration) on an experimental system similar to that described above but using as the indicator electrode a suitable sodium ion selective electrode (Orion, model 84-11) $\left(\mathrm{C}_{\mathrm{Na}}=2.0 \times 10^{-5}-6.7 \times 10^{-3} \mathrm{~mol} \mathrm{dm}{ }^{-3} ; \mathrm{C}_{\mathrm{L}}=2.4 \times 10^{-4}-1.1 \times 10^{-3} \mathrm{~mol} \mathrm{dm}^{-3}\right)$. The potential measurements were carried out with a Philips model PW 9416 potentiometer. The indicator electrodes were regularly calibrated using standard solutions of silver nitrate or sodium nitrate and the treatment of the data revealed a behaviour of the electrodes very close to the nernstian type response.

In order to test the reliability of this competition method, stability constants of crown ether $18 \mathrm{C} 6$ complexes with $\mathrm{Ag}^{+}, \mathrm{Na}^{+}$and $\mathrm{K}^{+}$have been determined by both direct and competitive methods. A good agreement was found comparing calculated with literature values $[22,23]$.

For each system the chemical model and the stability constants of the formed complexes in solution were determined by fitting the potentiometric data obtained from the titrations using the Superquad program [24]. We have introduced some modifications to take account of the experimental conditions of our work. We have calculated the stability constants of the silver complexes and then, using these constants as fixed values, we obtained the unknown values of the binding constants of the alkali cation complexes.

\section{Results and Discussion}

The complexing species that are the object of this study are constituted by a cyclic polyether coupled to an anthraquinone unit and are designed by AQ18C6 and AQ21C7 (Fig. 1). The macrocyclic cavity is a polydentate chelating system and the binding with the alkali cations will be dominated by multiple oxygen atom-cation electrostatic interactions. 


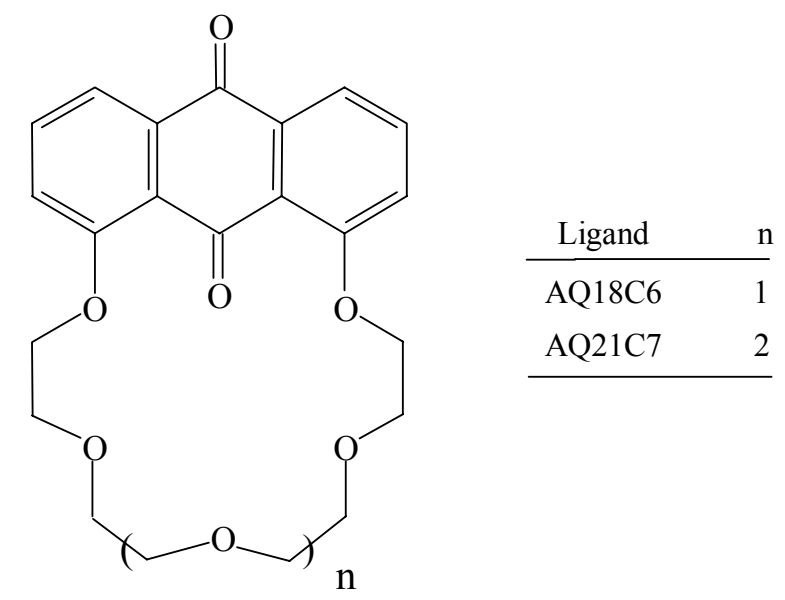

Figure 1. Chemical structures of crown ether derivatives, AQ18C6 $(n=1)$ and AQ21C7 $(\mathrm{n}=2)$.

Table 1. Stability constants $(\log \beta)$ for the complexes of alkali metal ions and silver ion with AQ18C6 and AQ21C7 ligands in methanol ${ }^{(\mathrm{a})(\mathrm{b})(\mathrm{c})}\left(\mathrm{t}=25^{\circ} \mathrm{C}, \mathrm{I}=0.1 \mathrm{~mol} \mathrm{dm}^{-3}\right.$ in TBAP).

\begin{tabular}{|c|c|c|c|c|}
\hline \multirow{2}{*}{$\begin{array}{l}\text { Metal } \\
\text { ion }\end{array}$} & \multirow{2}{*}{$\frac{\mathrm{AQ} 18 \mathrm{C} 6}{\log \beta_{11}}$} & \multicolumn{3}{|c|}{$\mathrm{AQ} 21 \mathrm{C} 7$} \\
\hline & & $\log \beta_{11}$ & $\log \beta_{12}$ & $\log \beta_{21}$ \\
\hline $\mathrm{Li}^{+}$ & $2.76 \pm 0.04$ & $2.02 \pm 0.04$ & - & - \\
\hline $\mathrm{Na}^{+}$ & $3.05 \pm 0.04$ & $2.62 \pm 0.08$ & - & - \\
\hline $\mathrm{Na}^{+(\mathrm{d})}$ & $3.10 \pm 0.08$ & $2.56 \pm 0.04$ & - & - \\
\hline $\mathrm{K}^{+}$ & $3.93 \pm 0.08$ & $3.08 \pm 0.05$ & - & - \\
\hline $\mathrm{Rb}^{+}$ & $3.78 \pm 0.04$ & $3.43 \pm 0.09$ & - & $6.74 \pm 0.20$ \\
\hline $\mathrm{Cs}^{+}$ & $3.58 \pm 0.04$ & $4.07 \pm 0.09$ & - & $7.89 \pm 0.19$ \\
\hline $\mathrm{Ag}^{+(\mathrm{e})}$ & $2.74 \pm 0.08$ & $2.78 \pm 0.04$ & $4.92 \pm 0.08$ & - \\
\hline
\end{tabular}

(a) Values obtained with the selective electrode of silver/silver sulphide using a competitive potentiometric titration.

(b) $\beta_{11}, \beta_{12}$ and $\beta_{21}$ refer to the equilibrium constants of the complex formation reactions between the cation $\left(\mathrm{M}^{+}\right)$and ligand molecule $(\mathrm{L}), \mathrm{L}+\mathrm{M}^{+} \rightarrow \mathrm{LM}^{+}, \mathrm{L}+2 \mathrm{M}^{+} \rightarrow \mathrm{LM}_{2}{ }^{2+}$ and $2 \mathrm{~L}+\mathrm{M}^{+} \rightarrow \mathrm{L}_{2} \mathrm{M}^{+}$, respectively.

(c) Concentration units used in stability constants are given in $\mathrm{mol} \mathrm{dm}^{-3}$.

(d) Value obtained with the selective electrode of sodium by direct potentiometric titration.

(e) Value obtained with the selective electrode of silver/silver sulphide by direct potentiometric titration.

Under our experimental conditions, the chemical model obtained from the computational results has indicated the formation of complexes with a 1:1 composition (ligand to metal) for all studied systems, while 2:1 complexes were found only for some systems of the AQ21C7 ligand. In these two solvents and for the concentrations of alkali salts used in this study, the tendency to form ion pairs is minimal and it is assumed that their presence does not influence the calculated stability constants [25]. 
The values obtained for the stability constants and presented in Tables 1 and 2 indicate that the most stable 1:1 complexes are formed by the cations, $\mathrm{K}^{+}$with AQ18C6 and $\mathrm{Cs}^{+}$ with AQ21C7, independent of the solvent. In spite of the type of interactions involved on the complex formation, the cations with larger effective ionic potential are not the ones that will bind more strongly to the oxygen atoms of the ligands. Thus, there will be more relevant factors that may contribute for the complexation stability.

The AQ18C6 ligand is more selective for the $\mathrm{K}^{+}$ion (diameter=2.76 $\AA$ )[26] among the alkali cations (Figs. 2 and 3).

Table 2. Stability constants $(\log \beta)$ for the complexes of alkali metal ions and silver ion with AQ18C6 and AQ21C7 ligands in acetonitrile ${ }^{(\mathrm{a})(\mathrm{b})(\mathrm{c})}\left(\mathrm{t}=25^{\circ} \mathrm{C}, \mathrm{I}=0.1 \mathrm{~mol} \mathrm{dm}^{-3}\right.$ in TBAP).

\begin{tabular}{cccccc}
\hline \multirow{2}{*}{$\begin{array}{c}\text { Metal } \\
\text { ion }\end{array}$} & AQ18C6 & & \multicolumn{3}{c}{$\mathrm{AQ21C7}$} \\
\cline { 2 - 3 } \cline { 4 - 6 } & $\log \beta_{11}$ & & $\log \beta_{11}$ & $\log \beta_{12}$ & $\log \beta_{21}$ \\
\hline $\mathrm{Li}^{+}$ & $3.16 \pm 0.04$ & & $2.50 \pm 0.04$ & - & - \\
$\mathrm{Na}^{+}$ & $3.67 \pm 0.08$ & & $2.92 \pm 0.09$ & - & - \\
$\mathrm{K}^{+}$ & $4.07 \pm 0.05$ & & $3.25 \pm 0.08$ & - & - \\
$\mathrm{Rb}^{+}$ & $3.59 \pm 0.08$ & & $3.51 \pm 0.07$ & - & $7.32 \pm 0.18$ \\
$\mathrm{Cs}^{+}$ & $3.40 \pm 0.04$ & & $3.87 \pm 0.09$ & - & $7.73 \pm 0.20$ \\
$\mathrm{Ag}^{+}$ & $3.34 \pm 0.04$ & & $2.72 \pm 0.06$ & $6.56 \pm 0.10$ & - \\
\hline
\end{tabular}

(a) Values obtained with the silver metal electrode using a competitive potentiometric titration.

(b) $\beta_{11}, \beta_{12}$ and $\beta_{21}$ refer to the equilibrium constants of the complex formation reactions between the cation $\left(\mathrm{M}^{+}\right)$and ligand molecule $(\mathrm{L}), \mathrm{L}+\mathrm{M}^{+} \rightarrow \mathrm{LM}^{+}, \mathrm{L}+2 \mathrm{M}^{+} \rightarrow \mathrm{LM}_{2}{ }^{2+}$ and $2 \mathrm{~L}+\mathrm{M}^{+} \rightarrow \mathrm{L}_{2} \mathrm{M}^{+}$, respectively.

(c) Concentration units used in stability constants are given in $\mathrm{mol} \mathrm{dm}^{-3}$.

(d) Values obtained with the silver metal electrode by direct potentiometric titration.

The appropriate size of this cation for the cavity of AQ18C6 (ring cavity size $\cong 2.77 \AA$ ) [22] allows to it be symmetrically positioned in the plane of the macroring donor atoms and to induce a more efficient interaction with all the oxygen atoms and in a ligand conformation without introducing large strains in the ring bonds [23,27]. The $\mathrm{Li}^{+}$and $\mathrm{Na}^{+}$ions induce the less stable complexes with AQ18C6 ligand in spite of their relatively higher charge density. Since $\mathrm{Li}^{+}$ion [26] is too small compared with the size of the macrocyclic cavity, possibly only some of the oxygen atoms participate effectively on the coordination to the metal ion [22,28]. Also, the distances and orientation of the electrons of the electrodonor atoms should not allow the best position 
for the coordination to the $\mathrm{Li}^{+}$ion (and also to the $\mathrm{Na}^{+}$ion); this combined with the higher solvation energy of the cation makes AQ18C6 $\mathrm{Li}^{+}$the weakest complex of all alkali cations [29]. $\mathrm{Rb}^{+}$and $\mathrm{Cs}^{+}$ions have smaller affinity than $\mathrm{K}^{+}$ion for AQ18C6 because they are too large to be accommodated into the cavity of this molecule. Thus, both ions may occupy a position displaced from the plane of the electrodonor atoms, (probably above of the plane), not interacting as strongly with the oxygen atoms as the $\mathrm{K}^{+}$ion $[30,31]$.

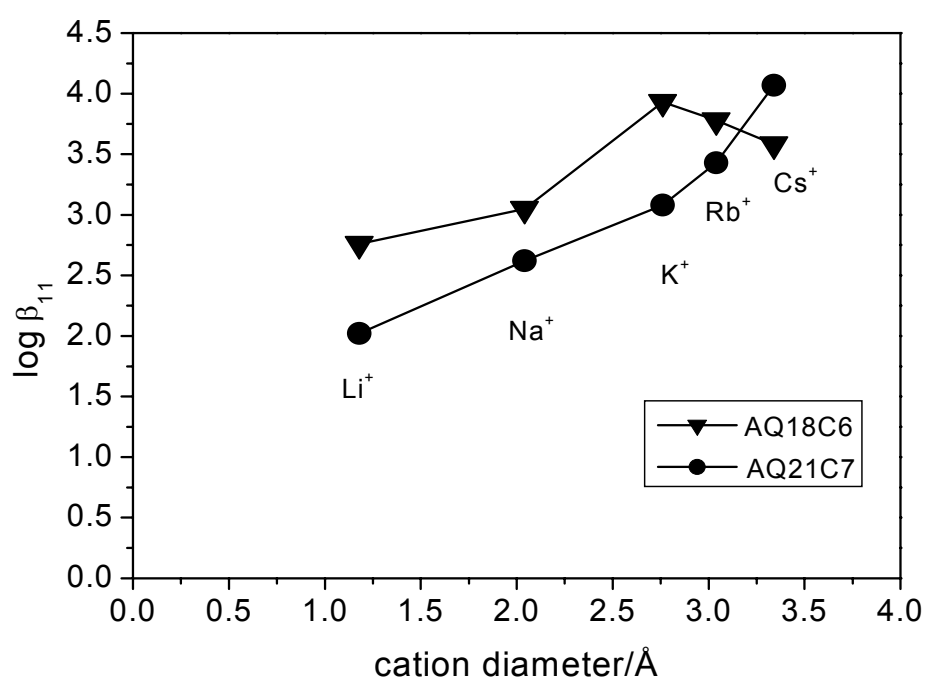

Figure 2. Stability constants $\left(\log \beta_{11}\right)$ of the alkali ion complexes of AQ18C6 and AQ21C7 in methanol vs. cation diameter.

The cavity of the AQ21C7 molecule (size $\cong 3.40 \AA$ ) [22] is large enough to allow the entry of any alkali cation, however the ligand is more selective for the $\mathrm{Cs}^{+}$ion. This cation has the proper dimension (diameter=3.40 $\AA$ ) [26] to fit in the ring cavity of AQ21C7, which favours the participation of all oxygen atoms of the macroring cavity on the coordination, and leads to a more favourable stabilisation. All other alkali cations are too small comparatively to the cavity of $\mathrm{AQ} 21 \mathrm{C} 7$, and form weaker complexes (Figs. 1 and 2). Their stability decreases with the decrease of the cation size, as is the case of the smaller ion $\mathrm{Li}^{+}$, which forms the least stable complex with AQ21C7 for the reasons given above.

The results presented in the Tables 1 and 2 show that the stability of the silver complexes is smaller than those of the alkali ions of comparable size $\left(\mathrm{Na}^{+}\right.$and $\left.\mathrm{K}^{+}\right)$. The 
binding of these cations to the donor atoms of the ligands involves forces that are essentially of electrostatic nature, whereas covalent interactions of smaller strength are predominant when $\mathrm{Ag}^{+}$is bound. In addition, $\mathrm{Ag}^{+}$ion is more strongly solvated in methanol and particularly in acetonitrile than the comparable alkali cations [32]. The silver ion complexes have very similar stability regardless of the size and number of oxygen donor atoms of the ligand, probably due to the influence of the weak interactions $\mathrm{Ag}^{+}-\mathrm{O}$, with the complexes of $\mathrm{AQ} 18 \mathrm{C} 6$ in acetonitrile being an exception. It is also interesting to note that on the chemical model obtained from the experimental data, the complexes $\mathrm{LAg}^{+}$and $\mathrm{LAg}_{2}{ }^{2+}$ with the Q21C7 ligand have been refined in contrast to tendency of the alkali metals. The use in solution of larger $\mathrm{Ag}^{+} / \mathrm{L}$ than $\mathrm{M}^{+} / \mathrm{L}$ concentration ratio is a probable reason.

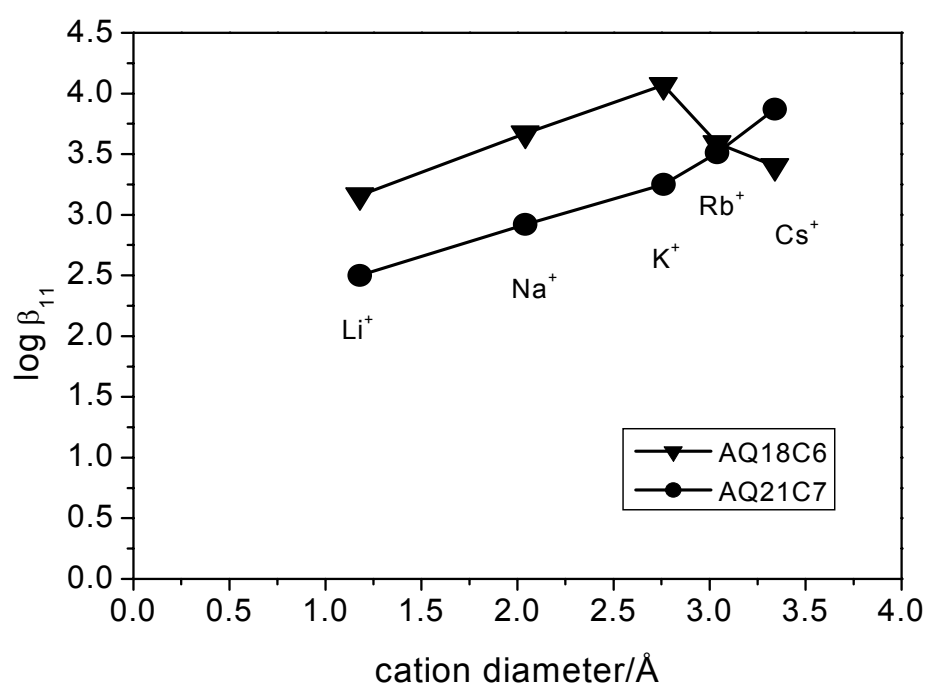

Figure 3. Stability constants $\left(\log \beta_{11}\right)$ of the alkali ion complexes of AQ18C6 and $\mathrm{AQ} 21 \mathrm{C} 7$ in acetonitrile vs. cation diameter.

The desolvation of the species involved on the complexation process is another factor that may influence the thermodynamic stability of the complexes, although the ligandsolvent interactions have a much smaller influence than that of the cations, especially in acetonitrile [23]. The appropriate fit of $\mathrm{K}^{+}$ion into the macrocyclic cavity of the AQ18C6 molecule should probably contribute to a comparatively more extensive desolvation of $\mathrm{K}^{+}$relatively to the other alkali cations. Therefore, the entropic effect should bring an overall more negative free energy of complexation. Calorimetric measures are in progress to clear this point. The stronger solvation of $\mathrm{Li}^{+}$and $\mathrm{Na}^{+}$ 
should not be sufficiently compensated by cation-ligand interactions because the AQ18C6 molecule should have its donor atoms at distances far enough to form optimum oxygen-cation interactions, thus resulting weaker desolvations. On these complexes the surface charge is not as well shielded from the surrounding solvent molecules and there can be a residual solvation of the complexed cation into the ligand cavity, which weakens the cation-ligand electrostatic interactions [33]. The desolvation contribution for the free energy of complexation of the largest and more weakly solvated $\mathrm{Rb}^{+}$and $\mathrm{Cs}^{+}$ions will also be of a smaller value because they do not fit into the macrocyclic cavity of AQ18C6.

In the macroring the increase of one oxygen-donor atom that can participate on the binding $\left(-\mathrm{CH}_{2} \mathrm{CH}_{2} \mathrm{O}\right.$ - subunit) and the consequent larger size of the macrocyclic cavity of AQ21C7 as compared with AQ18C6, results in some loss of complexation stability and changes the ligand selectivity as is shown in Figs. 2 and 3. All alkali cations have a smaller size than the macrocyclic cavity of AQ21C7, thus a likely reason for the lower affinity of this molecule for the alkali cations relatively to AQ18C6, can be the less good fit of each cation into the macrocyclic cavity of the AQ21C7 molecule as compared to its fit in the AQ18C6 cavity. The largest distance between the coordinated metal ion and the donor atoms and a less favourable orientation of the electrons of the donor atoms should result in weaker interactions. On the other hand, a smaller number of solvating molecules are replaced on the cation when it interacts with the AQ21C7 ligand, thus contributing to a larger free energy of the complexes of this molecule. The exception to this tendency occurs for the $\mathrm{Cs}^{+}$ion because it can fit better in the cavity of AQ21C7 than in the cavity of AQ18C6, when compared to the fit of all the other alkali cations. As a consequence it forms more stable complexes with AQ21C7 than with AQ18C6.

Although 1:1 complexes have been detected for all systems, the formation of species with a 2:1 stoichiometry (Tables 1 and 2) has only been identified when there is an marked excess of the AQ21C7 ligand and for the largest cations $\left(\mathrm{Rb}^{+}, \mathrm{Cs}^{+}\right)$. Unsubstitued crown ethers do not form 2:1 complexes even if present in excess. The 2:1 complexes of AQ21C7 probably have a structure where the cation makes the bridge between two ligand molecules [23]. When the complexed ion is smaller than the molecule cavity and does not fit as well $\left(\mathrm{Li}^{+}, \mathrm{Na}^{+}\right)$, then the interaction with a second molecule is not favoured. 
Although methanol and acetonitrile possess similar polarity, they differ in both hydrogen bonding ability and donicity [34] and two distinct behaviours have been verified in the complexation of the alkali cations on these two solvents as is shown in Tables 1 and 2. Methanol has larger solvating capacity towards $\mathrm{Li}^{+}$and $\mathrm{Na}^{+}$cations [32] and thus can compete with the ligands more readily than acetonitrile. When the medium is changed from methanol to acetonitrile the interaction between the ligands and those cations is strengthened and higher binding constants should be expected in acetonitrile than in methanol. The complexes of cations of larger size, $\mathrm{Rb}^{+}$and $\mathrm{Cs}^{+}$, follow a different tendency. Owing to their smaller ionic potential, $\mathrm{Cs}^{+}$and $\mathrm{Rb}^{+}$ions are less hard acids than $\mathrm{Li}^{+}, \mathrm{Na}^{+}$or $\mathrm{K}^{+}$ions and may interact sufficiently more strongly with acetonitrile nitrogen atom than with methanol, $[33,35]$ therefore resulting in a decrease in the stability sequence, AQ18C6 complexes (methanol) $>$ AQ18C6 complexes (acetonitrile) for $\mathrm{Rb}^{+}$and $\mathrm{Cs}^{+}$.

The results obtained show that the complexation stability of the alkali cations is decreased by the incorporation of an anthraquinone unit into crown ether. Compared to the corresponding unsubstituted crown ether complexes, $18 \mathrm{C} 6$ and $21 \mathrm{C} 7$, there is some decrease in the stability of the AQ18C6 and AQ21C7 complexes, but little changes in the cation selectivity [10]. The presence of the anthraquinone unit reduces the basicity of the oxygen atoms especially next to it and makes the macroring more organised in the complexation process when compared with the larger flexibility of the ring cavity for the corresponding unsubstituted crown ethers, thus contributing for the weakness of the binding.

\section{References}

1. J.M. Lehn, Angew. Chem. Int. Ed. Engl. 27 (1988) 89.

2. D.J.Cram, Science 240 (1988) 760.

3. L.F. Lindoy, The Chemistry of Macrocyclic Ligand Complexes, Cambridge University Press, Cambridge, 1989.

4. Y. Inoue, G.W. Gokel (Eds.), Cation Binding by Macrocycles: Complexation of Cationic Species by Crown Ethers, Marcel Dekker, New York, 1990.

5. F. Vogtle, E. Weber (Eds.), Host Guest Complex Chemistry, in Topics in Current Chemistry, Springer-Verlag, Berlin, 1984 (Vol. 121), 1985 (Vol. 128). 
6. B.G. Cox, H. Schneider, Coordination and Transport Properties of Macrocyclic Compounds in Solution, Elsevier, Amsterdam, 1992.

7. H.C. Visser, D.N. Reinhoudt, F. de Jong, Chem. Soc. Rev. 23 (1994) 75.

8. Y. Umezawa (Ed.), Handbook of Ion-Selective Electrodes: Selectivity Coefficients, CRC Press, Boca Raton, Florida, 1990.

9. P. Bühlmann, E. Pretsch, E. Bakker, Chem. Rev. 98 (1998) 1593.

10. R.M. Izatt, J.S. Bradshaw, S.A. Nielsen, J.D. Lamb, J.J. Christensen, D. Sen, Chem. Rev. 85 (1985) 271.

11. R.D. Hancock, J. Chem. Ed. 69 (1992) 615.

12. R.D. Hancock, A.E. Martell, Chem. Rev. 89 (1989) 1875.

13. R.M. Izatt, K. Pawlak, J.S. Bradshaw, R.L. Bruening, Chem. Rev. 95 (1995) 2529.

14. V.P. Solov’ev, N.N. Strakhova, O.A. Raevsky, V. Rüdiger, H.J. Schneider, J. Org. Chem. 61 (1996) 5221.

15. J.M. Caridade Costa, J. Jeyashri, D. Bethell, J. Electroanal. Chem. 351 (1993) 259.

16. J.M. Caridade Costa, D. Bethell, J. Coord. Chem. 46 (1999) 551.

17. A. Gustowski, M. Delgado, V.J. Gatto, L. Echegoyen, G.W. Gokel, J. Am. Chem. Soc. 108 (1986) 7553.

18. Z. Chen, O.F. Schall, Y. Li, G.W. Gokel, L. Echegoyen, J. Am. Chem. Soc. 114 (1992) 444.

19. D.N. Bhattacharyya, C.L. Lee, J. Smid and M. Szwarc, J. Phys. Chem. 69 (1965) 608.

20. B.G. Cox, H. Schneider, J. Stroka, J. Am. Chem. Soc. 100 (1978) 4746.

21. D.A. Gustowski, V.J. Gatto, J. Mallen, L. Echegoyen, G.W. Gokel, J. Org. Chem. 52 (1987) 5172.

22. J.D. Lamb, R.M. Izatt, C.S. Swain, J.J. Christensen, J. Am. Chem. Soc. 102 (1980) 475.

23. H.J. Buschmann, J. Solution Chem. 17 (1988) 277.

24. P. Gans, A. Sabatini, A. Vacca, J. Chem. Soc., Dalton Trans. (1985) 1195.

25. H.J. Buschmann, E. Cleve, E. Schollmeyer, J. Solution Chem. 23 (1994) 569.

26. R.D. Shannon, Acta Crystallogr. A32 (1976) 751.

27. G.W. Gokel, Chem. Soc. Rev. 21 (1992) 39.

28. H.J. Buschmann, H. Dong, E. Schollmeyer, J. Coord. Chem. 30 (1993) 311.

29. E. Karkhaneei, J. Zolgharnein, A. Afkhami, M. Shamsipur, J. Coord. Chem. 46 (1998) 1. 
30. G. Wipff, P. Weiner, P. Kollman, J. Am. Chem. Soc. 104 (1982) 3249.

31. B.G. Cox, P. Firman and H. Schneider, Inorg. Chim. Acta, 69 (1983) 161.

32. Y. Marcus, Ion Solvation, J. Wiley, Chichester, 1985.

33. M.K. Chantooni, G. Roland, I.M. Kolthoff, J. Solution Chem., 17 (1988) 175.

34. V. Gutmann, The Donor Acceptor Approach to Molecular Interactions, Plenum Press, New York, 1978.

35. R.G. Pearson, Coord. Chem. Rev. 100 (1990) 403. 